\title{
SER CUIDADOR FAMILIAR DO PORTADOR DE DOENÇA DE ALZHEIMER: VIVÊNCIAS E SENTIMENTOS DESVELADOS
}

\author{
Kátia Lílian Sedrez Celich ${ }^{1}$, Maribel Batistella²
}

\begin{abstract}
RESUMO: Neste estudo buscou-se descrever as vivências e os sentimentos de ser um cuidador familiar do portador da Doença de Alzheimer (DA). Caracteriza-se numa pesquisa qualitativa com abordagem fenomenológica. Foram entrevistados cinco familiares, na condição de cuidador principal de idosos com esta demência. A análise desvelou quatro temas: O ser-aí do cuidador; A vivência de sercom o idoso; O Estar - só e Afetividade. Conclui-se que ser cuidador principal do idoso que demencia é um desafio, principalmente quando aquele não recebe suporte familiar ou social. O ser-aí desse cuidador se fragiliza e apresenta uma sobrecarga física e emocional, em que cuida porque não encontra outra saída (facticidade). Ele procura ter paciência, tolerância, amor e respeito por esse Ser. Necessário é que esse cuidador seja compreendido em sua existencialidade e apoiado nesta trajetória de cuidado.
\end{abstract}

PALAVRAS-CHAVE: Idoso; Doença de Alzheimer; Família.

\section{FAMILY CAREGIVER OF ALZHEIMER'S DISEASE PATIENT: LIFE EXPERIENCE AND FEELINGS REVEALED}

\begin{abstract}
The objective of this paper is to describe the life experience and feelings of the family caregiver of Alzheimer's Disease patient. This is a qualitative study with phenomenological approach. Five female family members that are the principal caregivers of five elderly with this dementia were interviewed. Four themes describing the life experience and feelings of the participants were revealed: The caregiver herself; Life experience with the elderly; Loneliness; Affectivity. We concluded that being the principal caregiver of a dement elderly is a challenge, specially when she does not receive familiar or social support. Her being gets fragile and she gets physically and emotionally stressed and has to care the patient because there is no option (facticity), but tries to do it with patience, tolerance, love and respect. It is essential that these caregivers be understood and supported during this caring process.
\end{abstract}

KEYWORDS: Elderly; Alzheimer's disease; Family.

\section{SER CUIDADOR FAMILIAR DEL PORTADOR DE ENFERMEDAD DE ALZHEIMER: VIVENCIAS Y SENTIMIENTOS DESVELADOS}

RESUMEN: En este estudio, se ha buscado describir las vivencias y los sentimientos de ser un cuidador familiar del portador de la Enfermedad de Alzheimer (DA). Se caracteriza en una pesquisa cualitativa con abordaje fenomenológico. Fueron entrevistados cinco familiares cuidadores principales de mayores con esta demencia. El análisis ha desvelado cuatro temas: el "ser-ahí" del cuidador; La vivencia del "ser-con" el mayor; El estar solo; Afectividad. Se concluyó que ser cuidador principal del mayor con demencia es un desafío, principalmente cuando no recibe soporte familiar o social. El "ser-ahí" de ese cuidador se fragiliza y presenta una sobrecarga física y emocional, que lo lleva a cuidar porque no encuentra otra salida (facticidad). Él busca tener paciencia, tolerancia, amor y respeto por ese Ser. Necesario es que ese cuidador sea comprendido en su existencialidad y apoyado en esa trayectoria de cuidado.

PALABRAS CLAVE: Anciano; Enfermedad de Alzheimer; Familia.

${ }^{1}$ Doutoranda em Gerontologia Biomédica pela Pontifícia Universidade Católica do Rio Grande do Sul-PUCRS. Mestre em Enfermagem. Professora do Curso de Graduação em Enfermagem da Universidade Regional Integrada do Alto Uruguai e das Missões - Campus de Erechim-RS.

${ }^{2}$ Acadêmica do nono semestre do Curso de Enfermagem da Universidade Regional Integrada do Alto Uruguai e das Missões - Campus de Erechim-RS.

Autor correspondente:

Kátia Lilian Sedrez Celich

Rua Silveira Martins, 638 ap. 04 - 99700-000 - Erechim-RS Recebido em: 28/06/07

Email: celich@clicalpha.com.br 


\section{INTRODUÇÃO}

Com o aumento da expectativa de vida da população é notório observar o envelhecimento do ser humano. Tal acontecimento ocasiona transformações profundas na sociedade, uma vez que as políticas públicas ainda são insatisfatórias diante das reais necessidades da pessoa idosa. Faz-se necessário debruçar sobre as questões referentes ao envelhecimento humano diante da magnitude dos problemas sociais, econômicos e de saúde que se apresentam.

O prolongamento da vida eleva a incidência de enfermidades crônico-degenerativas e incapacitantes, com possível dependência física, cognitiva e emocional. A demência é uma das maiores causas de morbimortalidade dentre as doenças crônicodegenerativas e, dentre os distúrbios demenciais, a Doença de Alzheimer (DA) é a mais freqüente ${ }^{(1)}$.

A doença de Alzheimer é "um distúrbio neurológico, degenerativo, progressivo que se caracteriza por perdas graduais da função cognitiva e por distúrbios no comportamento e afeto" ${ }^{(2: 152)}$. Essa patologia induz a alterações progressivas da memória, do julgamento e do raciocínio intelectual, tornando o indivíduo cada vez mais dependente, ou seja, fazendo com que necessite da ajuda de outra pessoa para sua sobrevivência ${ }^{(3)}$.

É indiscutível o impacto dessa doença na sociedade atual, uma vez que já é considerada a epidemia do século XXI, imputando sofrimento expressivo ao seu portador e à sua família, como cuidadora, exigindo novos ajustes em sua dinâmica de funcionamento, provocando sobrecarga física e emocional aos membros da família ${ }^{(1)}$.

Na grande maioria das situações é um familiar quem assume o papel de cuidador, tornado-se o cuidador principal, mesmo que, na maioria das vezes, não receba treinamento específico. Entende-se por cuidador principal aquele que fica responsável pela quase totalidade dos encargos e cuidados do idoso demenciado e a quem estão reservados os trabalhos de rotina ${ }^{(4)}$. Cuidar é o ato de assistir alguém ou prestar serviços quando esse necessita, sendo uma atividade complexa, focalizada em várias dimensões, sejam elas, éticas, psicológicas, sociais, físicas, tendo seus aspectos clínicos, técnicos e comunitários ${ }^{(5)}$.

Diante do exposto, pode-se inferir que nem todas as famílias possuem membros preparados para assumir a responsabilidade de ser um cuidador do portador da Doença de Alzheimer, já que o papel do cuidador é vital neste processo, uma vez que é o elo entre o doente e o meio externo. Por esse motivo, ser cuidador exige muito carinho, amor, respeito e, principalmente, paciência e compaixão. Nesse sentido, surge a inquietação: o que sente o cuidador familiar ao ter que assumir esse papel? Como esse cuidador percebe sua vivência nesse processo?

Com esse trabalho espera-se contribuir com os familiares , proporcionando momentos de reflexão em relação ao seu papel como cuidadores. Acredita-se que, dando-lhes oportunidade para que descrevam seus sentimentos e suas vivências, possam aliviar suas tensões e ansiedades, o que promoveria melhora no seu bem-estar favorecendo a sua condição de cuidador. Dessa forma, este estudo tem como objetivo descrever as vivências e os sentimentos de ser um cuidador familiar do portador da Doença de Alzheimer.

\section{METODOLOGIA}

O estudo orientou-se pela pesquisa qualitativa, com abordagem fenomenológica. A pesquisa qualitativa permite apreender e compreender a realidade vivenciada, as crenças e valores de cada pessoa, revelando o que está oculto em suas vivências ${ }^{(6)}$.

A pesquisa fenomenológica tem como objetivo compreender a essência do ser ou conhecer qual o significado das experiências por ele vivenciadas cotidianamente, demonstrando, através do discurso, o que o sujeito tem na consciência no momento em que vivencia este fenômeno, quer seja por meio da fala, escrita, gestos, silêncio, tonalidade da voz, o olhar e o movimento do corpo durante a entrevista ${ }^{(7)}$. No entender da fenomenologia a emoção é um sentimento que somente a pessoa que o vivenciou verdadeiramente sabe expressá-lo.

Os participantes do estudo foram cinco familiares (cuidador principal) do portador da Doença de Alzheimer, residentes na cidade de Erechim/RS. Esta pesquisa foi aprovada pelo Comitê de Ética e Pesquisa da Universidade Regional Integrada do Alto Uruguai e das Missões - Campus de Erechim, sob o parecer $\mathrm{n}^{\circ}$ 040/TCH/06. Tendo como registro no SISNEP o ${ }^{\circ}$ 0047.0.232.000-06. Todos que aceitaram fazer parte do estudo assinaram o Termo de Consentimento Livre e Esclarecido, no qual foi assegurada a confidencialidade, e que os resultados somente seriam utilizados para fins acadêmicos.

O instrumento utilizado para coleta das 
informações foi uma entrevista semi-estruturada, a qual oferece ao pesquisador um grande campo para que o mesmo possa ter liberdade de atuação e participação do que ousa pesquisar, permitindo a visualização de várias possibilidades de introduzir-se no mundo do fenômeno a ser descoberto ${ }^{(8)}$. As entrevistas foram gravadas e posteriormente transcritas na íntegra. Procurou-se, dessa forma, seguir as questões norteadoras que serviram de guia no processo de coleta das informações: Qual o seu elo de ligação com o familiar ao qual presta cuidados? Como passou a ser cuidador e há quanto tempo realiza este papel? Como é seu dia-a-dia como cuidador? Como você se sente ao cuidar deste familiar? As fitas de áudio contendo as gravações foram destruídas e as transcrições ficarão sob a guarda das pesquisadoras por cinco anos, após o que também serão inutilizadas.

Para análise dos dados utilizou-se a hermenêutica de Ricoeur ${ }^{(9)}$, pois a mesma permite que o pesquisador compreenda a magnitude do que há por trás das palavras utilizadas nos discursos. A análise hermenêutica tem por objetivo compreender o sentido da existência da humanidade. Desta forma, não se avalia somente a linguagem utilizada nas respostas, mas o que é oculto dentro dela. A hermenêutica é o estudo que busca perceber o ser como um todo, através da forma como expressa sua linguagem pela fala ou escrita, seus comportamentos simbólicos durante o discurso, "[...] mostrando a verdade que se oculta no aparente e, assim, compreender e interpretar o sentido produzido na linguagem"(10:46). Para tanto, seguiu-se os passos propostos por Crossetti ${ }^{(10)}$ e Motta ${ }^{(11)}$ descritos a seguir: leitura inicial do texto, distanciamento, análise estrutural, identificação da metáfora e apropriação.

Leitura inicial do texto - $\mathrm{O}$ início do estudo proposto tem por objetivo uma leitura de compreensão ingênua dos discursos, ou seja, buscar os primeiros significados obtidos com as observações e as entrevistas. Com isso, o pesquisador começa a construção dos significados contidos no discurso, sem questionar o que o participante descreve em seu texto. Nesse momento, organizou-se o material e a leitura feita tantas vezes quantas foram necessárias, com o objetivo de descrever as experiências e as vivências de ser um cuidador familiar de um portador da doença de Alzheimer.

Distanciamento - Nessa etapa, o pesquisador deve participar da interpretação dos discursos, mas manter afastados seus preconceitos e crenças, construídos durante sua existência, para que o sentido dos discursos seja preservado. Dessa forma, o pesquisador tem condição de refletir e desvelar os reais sentidos existentes.

Análise estrutural - Nesse momento, o pesquisador faz uma releitura profundamente crítica do que é aparente, ou seja, encontra a explicação, compreensão e interpretação da leitura realizada na primeira etapa, buscando o sentido do que está oculto nos discursos e na fala utilizada. O texto constitui a unidade de análise para a hermenêutica ${ }^{(9)}$.

Identificação da metáfora - Nessa etapa é objetivada uma criação momentânea de outra linguagem, que faz com que seja desvelado o que estava até o momento implícito nos discursos, dando um novo sentido à linguagem. É feita a utilização das metáforas que emergem da compreensão dos temas e subtemas propostos anteriormente.

Apropriação - Finalizando o processo de análise e interpretação das informações, o pesquisador está pronto para compreender as metáforas estabelecidas na fase anterior. A obscuridade contida no estudo vai ficando de lado, possibilitando uma visualidade mais ampla ${ }^{(11)}$. Após a compreensão dos discursos, as pesquisadoras podem apropriar-se da metáfora desvelada, isto é, descrever as vivências e os sentimentos de ser um cuidador familiar do portador da Doença de Alzheimer.

\section{ANÁLISE COMPREENSIVA À LUZ DA FENOMENOLOGIA}

Em relação à familiaridade, o estudo constatou que todas as cuidadoras eram mulheres (filhas). Esse fato pode estar associado a questões de gênero, uma vez que a mulher, ao longo da história, na grande totalidade das circunstâncias, é quem desenvolve o papel de cuidadora. Esse evento encontra apoio na afirmativa de que quase sempre é uma filha ou a esposa que passa a assumir o papel de cuidadora e responsável por aquela pessoa. A mulher tem instinto maternal; quando cuida de um doente torna-se meiga, compreensiva, além de ter uma capacidade muito grande de amor e desprendimento ${ }^{(12)}$.

A pesquisa evidenciou que as portadoras da DA apresentavam idade entre 80 e 86 anos e o tempo de demência oscilava entre 2 e 13 anos. Com o avançar da idade, as pessoas tornam-se mais vulneráveis às demências, sendo que a DA é a mais freqüente ${ }^{(13)}$.

A seguir, busca-se descrever as vivências e os sentimentos dos cuidadores familiares do portador da 
Doença de Alzheimer, numa aproximação à interpretação hermenêutica, sendo que este é um exercício de desvelamento progressivo até que se consiga descrever a essência do fenômeno.

\section{O ser-aí do cuidador}

Esse evento é descrito quando o familiar se percebe como ser humano que está no mundo com seu "próprio modo de ser" e com suas limitações. Este sentimento é manifestado nos seguintes discursos:

Eu sou a única pessoa aqui dos filhos, disponivel prá fazer esse trabalho; está sendo muito difícil, eu abandonei a minha casa, as minhas coisas [...] estou sendo sacrificada. Sinceramente, não sei até quando vou agüentar (E.1).

Eu tô assim muito cansada, não durmo direito, vou acabar ficando doente, já estive depressiva, durante a semana. Sou eu para cuidar, e final de semana também, qual a pessoa que agüenta isso? Sempre morei com a mãe, não casei, fiquei responsável pelos cuidados dela. Se fui a escolhida para carregar essa cruz, vou fazer o quê? (E.2).

Sou a filha mais velha, moro com a mãe já faz cinco anos. O meu dia-a-dia é muito difícil, muito cansativo e estressante. Ainda trabalho como merendeira em uma escola, não sei quanto tempo vou agüentar (E.3).

Eu me sinto muito feliz por estar cuidando de minha mãe, mas tenho passado por momentos dificeis, mas graças à Deus estou tendo força suficiente para enfrentar os dias e as noites. Tem horas que dá vontade de chutar tudo pro alto, dai eu olho pra ela e crio forças para continuar a minha missão. Obrigado meu Deus, por me deixar existir e resistir! Eu amo a minha mãe como ela é, para sempre (E.4).

Eu sou a filha mais nova de 10 irmãos. Passei a ser cuidadora porque, além de amar muito a minha mãe, era a única que morava com os pais. Tenho cuidadores profissionais que me auxiliam, pois são 13 anos de tratamento (E.5).

As narrativas fazem referência ao sofrimento cotidiano que estas cuidadoras estão vivenciando. Ao cuidar do familiar idoso, com quem se ocupam intensamente, apresentam um grande cansaço e enfrentam dificuldades, reconhecendo a necessidade de serem cuidadas, uma vez que afirmam não estarem conseguindo dormir, estarem depressivas, estressadas, terem abandonado seus lares. Esta situação é o que Heidegger $^{(14)}$ entende como facticidade - ele cuida porque não vê outra saída.

Ainda no pensamento heideggeriano, o homem é ao mesmo tempo ator e autor de sua própria história. Quando percebe tal evidência e assume esta enorme responsabilidade ontológica, pode mudar seu percurso $^{(10)}$. Diante dessa possibilidade, as cuidadoras podem sentir que há uma esperança, pois, à medida que (re)significarem essa experiência, poderão sentirse mais fortalecidas e encorajadas a continuar cuidando com dignidade desse familiar.

No entanto, um único familiar para desenvolver o cuidar é extremamente cansativo e estressante, como fica evidente nos desabafos desses cuidadores. Estudo como o de Pelzer ${ }^{(1)}$ demonstra que a DA, além de comprometer de maneira singular a vida do idoso, afeta a dinâmica e o funcionamento da família, sobrecarregando física e emocionalmente esses familiares, que geralmente têm que assumir o encargo de cuidar desse idoso sem ter recebido apoio, preparo ou treinamento específico.

É possível destacar que, com a doença, há um rompimento do modo de ser do cuidador no seu diaa-dia, o que o faz sentir-se como um estranho em um mundo que não lhe é mais familiar, e em condições tampouco por ele escolhidas. Assim, ele assiste ao desmoronar de seu cotidiano, o que lhe impõe um estado angustiante e de fragilidade.

\section{A vivência de ser-com o idoso}

Este acontecimento é desvelado quando o cuidador consegue romper a barreira da mera ocupação e passa a compreender a dimensão existencial deste ser que demencia. Tal evento pode ser evidenciado nas falas a seguir:

A mãe é uma pessoa super difícil, muito braba, não aceita as coisas. Tu vai dar comida, ela não tá com fome. Ai espera um pouquinho e diz que ninguém dá comida prá ela. E u procuro ter paciência (E.1).

[...] quando eu vou dar banho é um sofrimento, ela me bate, ela me morde. Não era isso que eu queria para minha família, mas ela é minha mãe (E.2).

Ela não toma banho sozinha, não se veste. Ainda 
que eu posso agradecer, porque a mãe não é agressiva, ela aceita o que eu faço. É muito difícil ver a mãe nesse estado, sabendo que ela sempre foi uma mulher ativa e independente [cuidadora chora] [...] eu me sinto muito feliz por cuidar dela. Ela sempre foi uma boa mãe (E.3).

São tantas as dificuldades. Cada dia é um dia, mas sempre problemáticas. Trabalho das 8 às 18 para o nosso sustento. Durante o dia conto com a ajuda de uma pessoa que presta cuidados à mãe, é uma pessoa muito dedicada, tem grande carinho por ela. Quando eu chego em casa, eu prefiro dar banho e dar a alimentação (E.4).

Sou professora. As horas de folga é dedicada à minha mãe, mas conto com uma pessoa cuidadora para dar banho e alimentação. Às vezes ela não aceita. É muito complicado (E.5).

Ao se refletir sobre as vivências das cuidadoras à luz do pensamento heideggeriano, inicialmente $o$ que chama a atenção é que esse "cuidar" que os familiares vivenciam está associado às atividades da vida diária, descrito como modo de ocupação.

Estas cuidadoras estão presas num aí que é passado (temporalidade): aquilo que o seu idoso familiar foi. E conseguem cuidar deste no tempo cronológico presente, que assume um modo de ser descompassado; assim, elas cuidam com paciência (tolerância).

Conhecer a doença e saber que há perda progressiva da memória, problemas de comportamento e de habilidade motora, troca de personalidade, alterações do sono, depressão, agressividade, entre outros é um fator que pode contribuir para entender, aceitar e ter paciência com o familiar ${ }^{(12)}$.

\section{O Estar - só}

É o momento em que o cuidador sente a necessidade de estar-com o mundo, pois só é possível estar-só para quem previamente está referindo aos outros. Este sentimento é expresso nos seguintes discursos:

Eu estou me sentindo bastante sozinha. 24 horas do dia quem está lá com ela sou eu (E.1).

Eu me sinto muito sozinha, porque as minhas amigas que vinham me visitar não vêm mais, porque quando começamos a conversar a mãe não entende e fica muito irritada, muito agressiva (E.2).

Procuro dar tudo à minha mãe dentro de minhas possibilidades, já que não posso contar com a ajuda dos meus irmãos que ela tanto cuidou com amor e carinho e hoje estamos sós (E.4).

Com o passar dos dias a mãe está cada vez mais dependente de nós. Para mim, infelizmente, é muito triste dizer que tem filhos que moram aqui próximo e nem se importam com ela. Estou muito cansada, desanimada, pois ninguém dos meus irmãos fica aqui para eu descansar um pouco. A mãe fala, fala e se você não falar com ela, fica irritada (E.5).

$\mathrm{Na}$ análise existencial heideggeriana, o homem, ao estar lançado no mundo, depara-se com situações que o fazem ter uma relação significativa com o seu meio, com as coisas, ou pessoas. Quando por uma razão ou outra, se instala uma ruptura nesta relação, esse homem sente-se inquieto, desamparado e sem rumo, sentindo seu cotidiano se despedaçar ${ }^{(10)}$. Este sentimento é desvelado pelas cuidadoras, uma vez que elas estão se sentindo sozinhas nessa condição de cuidadoras.

Os relatos ainda traduzem a solidão social que experimentam. O homem é um ser social que necessita do convívio com outros para continuar escrevendo sua história, portanto vivencia o mundo em presença com os outros ${ }^{(15)}$. A enfermagem, como profissão de cuidado tem um papel importante nesse momento, podendo articular atividades voltadas para a proteção e promoção da vida individual e familiar que contribuam para a aquisição de uma vida com qualidade ${ }^{(1)}$.

\section{Afetividade}

É o modo de sentir o outro e o mundo. Neste estar frente a frente com o portador da Doença de Alzheimer, o cuidador deixa fluir seus sentimentos e o desejo de manifestar seu amor por meio de cuidado, preocupação, respeito e solicitude. Este aspecto emerge ao se observar as seguintes afirmativas;

Eu não estou me sentindo muito bem, porque eu gostaria de cuidar dela com muito amor, carinho e paciência, mas não estou tendo tanta paciência como eu gostaria (E.1).

Meu maior sentimento é de culpa. Quando a mãe 
começou a desenvolver a doença ela só falava bobagens, não falava coisa com coisa. Eu xingava, mas não sabia que era da doença de Alzheimer que causava isso. Hoje, eu choro por ter feito certas coisas, mas depois que descobri como uma pessoa com Alzheimer deve ser cuidada, retribuo com muito cuidado, amor, carinho e compaixão, [...] apesar dela não me conhecer mais (E.3).

Cuido com muito amor e carinho, mas tem momentos que não é fácil (E.4).

Embora as dificuldades, para mim é um privilégio ser cuidadora de minha mãe. Me sinto muito bem, mas às vezes muito triste ao vê-la com tanta dificuldade com a perda da memória. Para mim é muito gratificante conviver com ela durante esse período em que ela tanto precisa de cuidados (E.5).

Para Heidegger ${ }^{(14)}$, nos encontramos sempre em uma situação afetiva, ou seja, estamos no mundo sempre em um determinado estado de ânimo. A afetividade abre ao homem o universo do seu existir. É através da afetividade que o ser humano se relaciona com o outro.

Fica evidente nos discursos das cuidadoras que elas desejam e querem cuidar com carinho, amor tolerância e paciência, respeitando estes idosos em sua existencialidade. O Ser-no-mundo é um Ser de cuidado, é zeloso, preocupado, é, pois, o estado primordial de ser do homem ${ }^{(10)}$. Portanto, essas cuidadoras são, na sua essência, seres de cuidado; logo, se preocupam com seu familiar. Isso pode ser entendido como solicitude, que para Heidegger é ter paciência, ter consideração, é perceber que a doença é uma facticidade em seu existir.

Assim, abre-se uma porta de esperança e de estímulo a essas cuidadoras para que continuem dedicando-se ao seu familiar e existindo em direção as suas possibilidades. A afetividade é uma dimensão constitutiva do Ser-no-mundo, sendo o próprio modo dele se relacionar e interagir com o outro. É o que cada um tem de mais profundo no seu existir ${ }^{(16)}$.

\section{CONSIDERAÇÕES FINAIS}

A Doença de Alzheimer afeta não só a pessoa, mas toda a família, especialmente o cuidador. Muitas vezes, é difícil para este encontrar com quem dividir seus sentimentos e o cuidado, já que, geralmente, o trabalho e a responsabilidade do dia-a-dia ficam nas mãos de uma única pessoa, que é sobrecarregada e, em muitas situações, se sente só e desprotegida.
O cuidador, como ser-aí, manifesta sua singularidade e assim permite ser olhado em sua existência e entendido em seus sentimentos, vivências e significados. Assim, está no mundo e precisa ser visto, ouvido e cuidado. O suporte a esse cuidador não pode ser negado. Ele não pode deixar de ser uma pessoa e passar a ser compreendido apenas como um cuidador, pois é, antes de tudo, Ser humano que necessita se realizar, ter liberdade, tomar decisões próprias.

Assim, como evidenciado no estudo de Pelzer ${ }^{(1)}$, também foi possível observar, no transcorrer das visitas domiciliares para a coleta de dados, o quanto estes familiares cuidadores estão desassistidos e sujeitos a uma sobrecarga emocional e física que os leva à exaustão, devido à ausência de vida social e à desestrutura financeira - que em algumas situações, os impede de contar com a ajuda de profissionais contratados - e a falta de uma rede social pública que lhes dê suporte.

O cuidador familiar do portador da doença de Alzheimer merece apoio e valorização por parte dos profissionais da saúde, na tentativa de reduzir a vulnerabilidade que a ambos está sendo imputada. Desta forma, a estratégia de Saúde da Família pode ser um suporte que se apresente a essa população. $\mathrm{O}$ enfermeiro, como membro dessa equipe, pode desenvolver grupos de ajuda ou redes que dêem suporte a esses familiares, com a finalidade de aliviar ou minimizar o seu sofrimento como cuidador principal.

A humanização, como princípio filosófico orientador das ações de enfermagem, permite aos profissionais que lidam com os idosos e seus familiares compartilhar de suas emoções e angústias, ajudandoos a ultrapassar o limite dessa fase da vida com dignidade. Chama-se especial atenção dos profissionais de saúde que podem desempenhar com eficiência suas funções se considerararem na assistência o cliente e seus familiares, seus componentes culturais de crenças, normas e práticas de saúde.

Esperamos que essa pesquisa venha contribuir com os profissionais, especialmente da enfermagem, no sentido de ampliar e manter o olhar e o cuidado, não só ao ser que demencia, mas estendê-lo aos familiares cuidadores. A enfermagem, como uma atividade essencialmente humanizada, deve cumprir esse importante papel social e, assim, buscar aliviar o sofrimento vivenciado por essas pessoas, nessa fase da vida. 


\section{REFERÊNCIAS}

1 Pelzer MT. Assistência cuidativa humanística de enfermagem para familiares cuidadores de idosos com doença de Alzheimer a partir de um grupo de ajuda mútua [tese]. Florianópolis (SC): Programa de Pós Graduação em Enfermagem/ UFSC; 2005.

2 Smeltzer, SC, Bare BG. Tratado de enfermagem médico-cirúrgica. $9^{\mathrm{a}}$ ed. Rio de Janeiro: Guanabara Koogan; 2002.

3 Associação Brasileira de Alzheimer. Velhice ou doença: identificando a demência. São Paulo: Folder; 2004.

4 Silveira TM. O sistema familiar e os cuidados com pacientes idosos portadores de distúrbios cognitivos. Textos sobre Envelhecimento. 2000 Jul;3(4):1-12.

5 Papaléo Netto M. Gerontologia: a velhice e o envelhecimento uma visão globalizada. São Paulo: Atheneu; 2005.

6 Minayo MCS. O desafio do conhecimento: pesquisa qualitativa em saúde. São Paulo: Hucitec; 2000.

7 Buógo M. Toque: um olhar sobre o encontro de cuidado [dissertação]. Porto Alegre (RS): Programa de Pós Graduação em Enfermagem/ UFRGS; 2000.

8 Triviños ANS. Introdução à pesquisa em ciências sociais. A pesquisa qualitativa em educação. São Paulo: Atlas; 1995.

9 Ricoeur P. Interpretações e ideologias. Rio de Janeiro: Francisco Alves; 1990.

10 Crossetti MGO. Processo de cuidar: uma aproximação à questão existencial na enfermagem [tese]. Florianópolis (SC): Programa de Pós Graduação em Enfermagem/UFSC; 1997.

11 Motta MGC. O ser doente no tríplice mundo da criança, família, hospital: uma visão fenomenológica das mudanças existenciais [tese]. Florianópolis (SC): Programa de Pós Graduação em Enfermagem/ UFSC; 1997.

12 Portugal IP. Doença de Alzheimer: como lidar com o doente. Porto Alegre: Autora; 2003.

13 Garrido R, Menezes P. O Brasil está envelhecendo: boas e más notícias por uma perspectiva epidemiológica. Rev Bras Psiq. 2002;24(1):3-6.

14 Heidegger M. Ser e tempo. Parte 2. $7^{\mathrm{a}}$ ed. Trad. Márcia de Sá Cavalcanti, Petrópolis: Vozes; 1993.

15 Celich KLS. Dimensões do processo de cuidar: a visão das enfermeiras. Rio de Janeiro: EPUB; 2004.

16 Caldas CP. Cuidando dos idosos que vivenciam uma síndrome demencial: a família como cliente da enfermagem. Texto Contexto Enferm. 2001 Mai/Ago; 10(2):68-93. 